Access provided by: The Bodl...

Cochrane Clinical Answers

\title{
Question:
}

\section{Can psychosocial interventions, given alone or added to treatment as usual, improve outcomes for people who misuse psychostimulants?}

Jonathan Livingstone-Banks

https://doi.org/10.1002/cca.2598 | 26 November 2019

\section{Answer}

Low-certainty evidence suggests that when compared with no treatment, psychosocial interventions for combatting psychostimulant misuse (such as cognitive-behavioral therapy, contingency management, motivational interviewing, interpersonal therapy, psychodynamic therapy, and 12-step facilitation) may increase abstinence rates at end of treatment (on average, 104 vs 49 per 1000 people), but this effect was less clear at longest follow-up (mean 12 months). Psychosocial interventions may also modestly decrease the frequency of drug intake compared with no treatment.

When compared with treatment as usual, the effect of psychosocial interventions on abstinence was uncertain at end of treatment (low-certainty evidence), and no studies assessed abstinence at longest follow-up nor frequency of drug intake.

\section{Comparisons}

\section{> OUTCOME 1.1 Withdrawal from treatment for any cause (follow-up mean 9 months)}

\section{Quality of the evidence}

The reviewers performed a GRADE assessment of the quality of evidence for this outcome at this time point and stated that the evidence was moderate certainty. See Summary of findings from Cochrane Review

Narrative result

24 RCTs with 3393 participants found that fewer people withdrew from treatment with any psychosocial treatment than with no intervention.[1] 
Subgroup analyses by specific psychosocial intervention (CBT, CM, MI, psychodynamic therapy and 12-step facilitation) were consistent with the main analysis for CBT, CM, MI and psychodynamic therapy, although lack of power means that only the analysis of CM (1740 participants) found a statistically significant difference between groups. The analysis of 112 participants receiving 12-step facilitation was underpowered.

\section{Relative effect or mean difference}

There was a statistically significant difference between groups, in favor of psychosocial treatment (RR $0.83,95 \% \mathrm{Cl}$ 0.76 to 0.91$)$.

\begin{tabular}{|c|c|c|c|c|c|}
\hline Sudy or subgroup & $\begin{array}{l}\text { any pohyococodal } \\
n / N\end{array}$ & $\begin{array}{c}\text { no intrvention } \\
n / N\end{array}$ & $\begin{array}{c}\text { Risk Raio } \\
\text { M-H,Random, } 95 \% \mathrm{Cl}\end{array}$ & Weight & $\begin{array}{c}\text { Risk Raio } \\
\text { M-H, Random, } 95 \%, \mathrm{Cl}\end{array}$ \\
\hline Baker 2001 & $2 / 32$ & $4 / 32$ & 1 & $0.6 \%$ & $2.00[0.67,5.92]$ \\
\hline Baker 2005 & $39 / 140$ & $20 / 74$ & + & $3.4 \%$ & $1.03[0.65,1.63]$ \\
\hline Carral 2012 & $19 / 58$ & $12 / 56$ & 千 & $1.9 \%$ & $1.58[0.85,2.94]$ \\
\hline Carrall 2014 & $13 / 47$ & $19 / 54$ & $\rightarrow$ & $2.1 \%$ & $0.79[0.44,1.41]$ \\
\hline Crit-Christoph 1909 & $162 / 243$ & $95 / 123$ & $\mathbf{E}$ & $29.5 \%$ & $0.86[0.78,0.88]$ \\
\hline Garcia-Femandez 2011 & $9 / 29$ & $12 / 29$ & $\longrightarrow$ & $1.5 \%$ & $0.75[0.37,1.50]$ \\
\hline Hagedom 2013 & $25 / 71$ & 3268 & + & $4.3 \%$ & $0.75[0.50,1.12]$ \\
\hline Higgins 1994 & $2 / 20$ & $7 / 20$ & - & $0.4 \%$ & $0.29[0.07,1.21]$ \\
\hline Higgins 2000 & $16 / 36$ & $16 / 34$ & + & $2.8 \%$ & $0.94[0.57,1.57]$ \\
\hline Higgins 2003 & $17 / 49$ & $34 / 51$ & + & $3.8 \%$ & $0.52[0.34,0.20]$ \\
\hline Ingersoll 2011 & $1 / 27$ & $2 / 26$ & 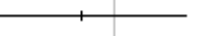 & $0.1 \%$ & $0.48[0.05,4.99]$ \\
\hline Kurby $199 e a$ & $10 / 44$ & $2 / 46$ & -1 & $1.1 \%$ & $1.31[0.57,3.01]$ \\
\hline Marsden 2008 & $22 / 168$ & $21 / 178$ & $\rightarrow$ & $2.3 \%$ & $1.11[0.84,1.94]$ \\
\hline Mckee 2007 & $12 / 3 e$ & $14 / 36$ & 十 & $1.9 \%$ & $0.81[0.44,1.51]$ \\
\hline Menza 2010 & $14 / 70$ & $11 / 57$ & $\longrightarrow$ & $1.5 \%$ & $1.04[0.51,2.10]$ \\
\hline Micheocon 2007 & $\alpha_{117}$ & $\alpha / 12$ & & & Not esimable \\
\hline Peiroe 2006 & $65 / 19 e$ & $67 / 190$ & $\#$ & $8.7 \%$ & $0.93[0.71,1.23]$ \\
\hline Peitjean 2014 & $10 / 29$ & $12 / 31$ & $\longrightarrow$ & $1.6 \%$ & $0.29[0.46,1.74]$ \\
\hline Pery $2005 a$ & $107 / 208$ & $134 / 208$ & \pm & $20.9 \%$ & $0.79[0.67,0.93]$ \\
\hline Pery $2005 b$ & $5 / 40$ & $6 / 37$ & + & $0.6 \%$ & $0.77[0.28,2.31]$ \\
\hline Peny 2007 & $6 / 57$ & $3 / 19$ & L & $0.4 \%$ & $0.67[0.18,2.41]$ \\
\hline Roll 2013 & $31 / 89$ & $12 / 29$ & + & $4.4 \%$ & $0.56[0.38,0.24]$ \\
\hline Seadeo Villa 2013 & $21 / 47$ & $21 / 35$ & + & $4.1 \%$ & $0.74[0.49,1.13]$ \\
\hline Stin 2009 & $17 / 97$ & $21 / 101$ & + & $2.2 \%$ & $0.24[0.47,1.50]$ \\
\hline \multicolumn{3}{|c|}{ 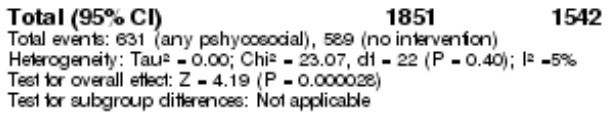 } & - & $100.0 \%$ & $0.83[0.76,0.91]$ \\
\hline
\end{tabular}

\section{Figure 1}

Forest plot from Cochrane Review

\section{Absolute effect}

293 per 1000 people (95\% Cl 269 to 320) with any psychosocial treatment compared with 353 per 1000 people with no intervention (calculated using median event rate).

\section{Reference}

Minozzi S, Saulle R, De Crescenzo F, Amato L. Psychosocial interventions for psychostimulant misuse. Cochrane Database of Systematic Reviews 2016, Issue 9. Art. No.: CD011866. DOI: 10.1002/14651858.CD011866.pub2. Search date November 2015 


\section{> OUTCOME 1.2 Continuous abstinence, end of treatment (follow-up mean 11 months)}

\section{Quality of the evidence}

The reviewers performed a GRADE assessment of the quality of evidence for this outcome at this time point and stated that the evidence was low certainty. See Summary of findings from Cochrane Review

\section{Narrative result}

Eight RCTs with 1241 participants found that more people had continuous abstinence at the end of treatment with any psychosocial than with no intervention.[2]

Subgroup analyses by specific psychosocial intervention (CBT or $\mathrm{CM}$ ) were consistent with the main analysis; most (1140) participants received CM.

\section{Relative effect or mean difference}

There was a statistically significant difference between groups, in favor of psychosocial treatment (RR 2.14, 95\% Cl 1.27 to 3.59$)$.

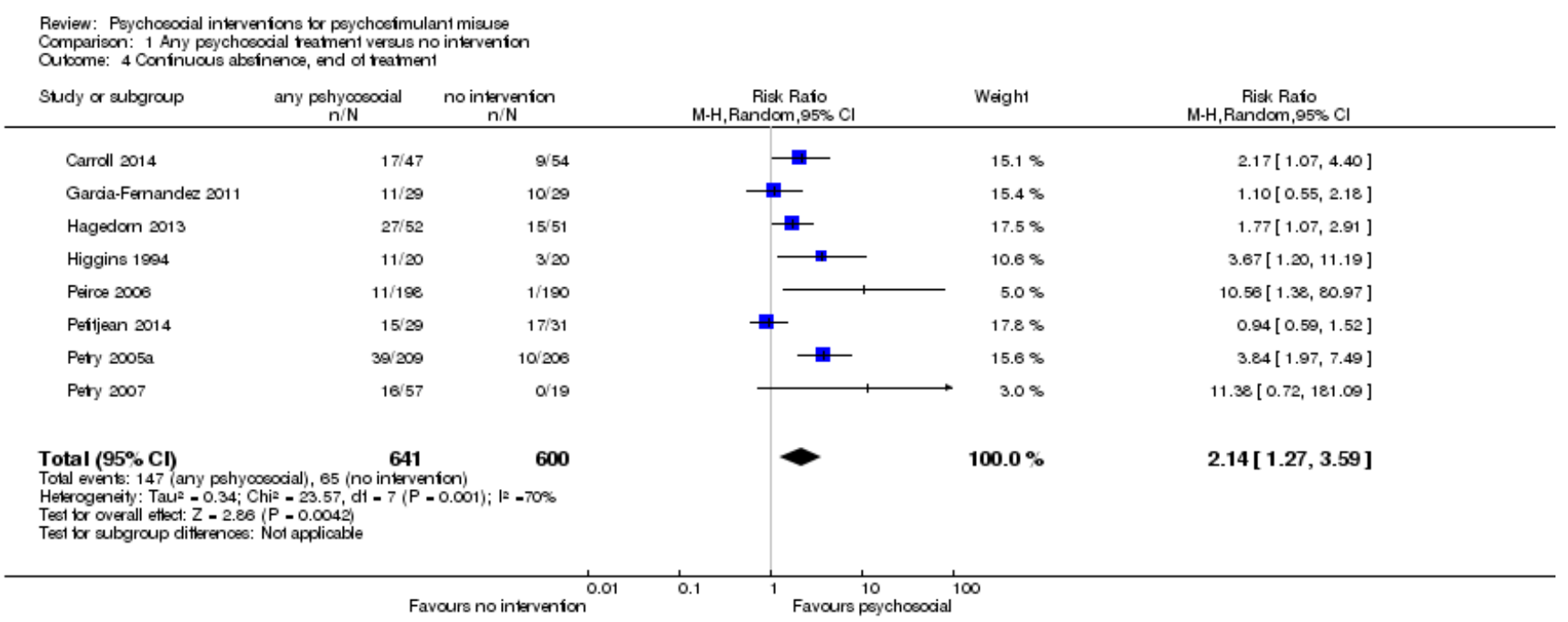

Figure 2

Open in figure viewer

Forest plot from Cochrane Review

\section{Absolute effect}

104 per 1000 people (95\% Cl 62 to 174) with any psychosocial treatment compared with 49 per 1000 people with no intervention (calculated using median event rate).

\section{Reference}

Minozzi S, Saulle R, De Crescenzo F, Amato L. Psychosocial interventions for psychostimulant misuse. Cochrane Database of Systematic Reviews 2016, Issue 9. Art. No.: CD011866. DOI: 10.1002/14651858.CD011866.pub2. Search date November 2015

\section{> OUTCOME 1.3 Continuous abstinence, longest follow-up (follow-up mean 12 months)}




\section{Quality of the evidence}

The reviewers performed a GRADE assessment of the quality of evidence for this outcome at this time point and stated that the evidence was low certainty. See Summary of findings from Cochrane Review

\section{Narrative result}

Four RCTs with 224 participants found no statistically significant difference between groups but the analysis may be underpowered.[3]

Subgroup analyses assessing CBT or MI separately also found no statistically significant difference between groups. The subgroup analysis of $\mathrm{CM}$ found in favor of psychosocial treatment, but the wide confidence intervals reduce certainty in this result. Click below for details.

\section{Relative effect or mean difference}

There was no statistically significant difference between groups (RR 2.12, 95\% Cl 0.77 to 5.86 ).

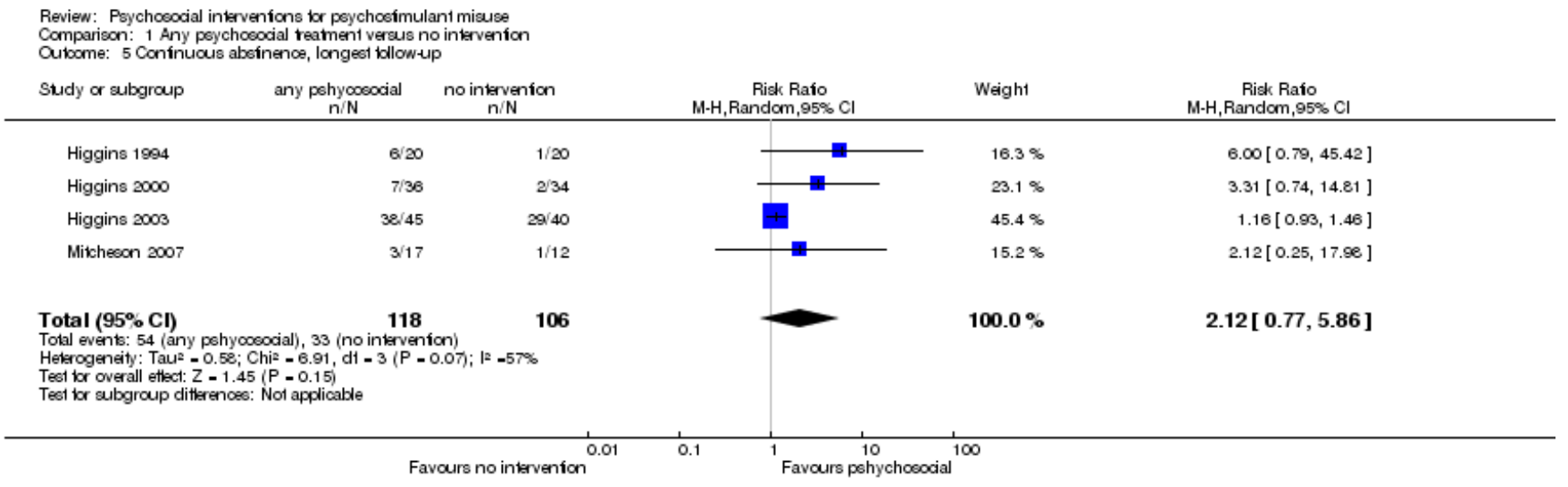

Figure 3

Open in figure viewer

Forest plot from Cochrane Review

\section{Absolute effect}

177 per 1000 people (95\% Cl 64 to 489) with any psychosocial treatment compared with 83 per 1000 people with no intervention (calculated using median event rate).

\section{Reference}

Minozzi S, Saulle R, De Crescenzo F, Amato L. Psychosocial interventions for psychostimulant misuse. Cochrane Database of Systematic Reviews 2016, Issue 9. Art. No.: CD011866. DOI: 10.1002/14651858.CD011866.pub2. Search date November 2015

\section{$>$ Subgroup analysis 1.3.1 Continuous abstinence, longest follow-up - [subgroup: CM]}

\section{Risk of bias of studies}


The reviewers did not perform a GRADE assessment of the quality/certainty of the evidence. Of the two studies, both failed to report adequate allocation concealment and/or random sequence generation and did not report adequate blinding of participants/carers/outcome assessors but both had low numbers of withdrawals.

\section{Narrative result}

Two RCTs with 110 participants found that more people had continuous abstinence at longest follow-up with contingency management than with no intervention.[4]

\section{Relative effect or mean difference}

There was a statistically significant difference between groups, in favor of psychosocial treatment (RR 4.08, $95 \% \mathrm{Cl} 1.22$ to 13.63$)$.

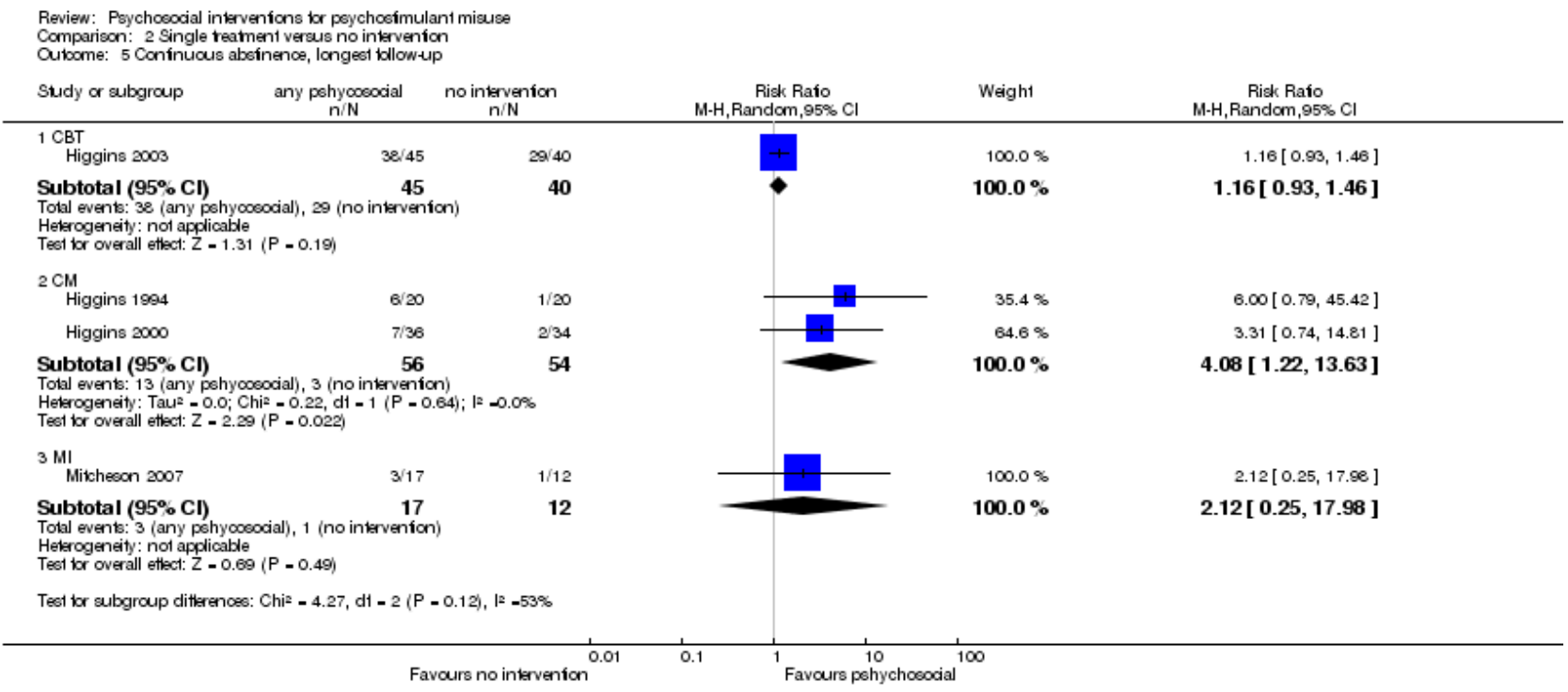

Figure 4

Open in figure viewer

Forest plot from Cochrane Review

\section{Absolute effect}

240 per 1000 people ( $95 \% \mathrm{Cl} 72$ to 802 ) with contingency management compared with 59 per 1000 people with no intervention.

\section{Reference}

Minozzi S, Saulle R, De Crescenzo F, Amato L. Psychosocial interventions for psychostimulant misuse.

Cochrane Database of Systematic Reviews 2016, Issue 9. Art. No.: CD011866. DOI:

10.1002/14651858.CD011866.pub2. Search date November 2015

\section{$>$ OUTCOME 1.4 Frequency of drug intake, longest follow-up (follow-up mean 12 months)}

\section{Risk of bias of studies}


The reviewers did not perform a GRADE assessment of the quality/certainty of the evidence. Of the four studies, three failed to report adequate allocation concealment and/or random sequence generation, none reported adequate blinding of participants/carers/outcome assessors and one had high or unclear numbers of withdrawals.

\section{Narrative result}

Four RCTs with 669 participants found that frequency of drug intake was modestly lower at longest follow-up with any psychosocial intervention than with no intervention.[5]

The reviewers calculated a standardized mean difference. These are hard to interpret clinically but rules of thumb in their interpretation suggest that 0.2 represents a small effect, 0.5 a moderate effect, and 0.8 a large effect (Cohen J. Statistical Power Analysis in the Behavioral Sciences (2nd edition). Hillsdale (NJ): Lawrence Erlbaum Associates, Inc., 1988).

Subgroup analyses by specific psychosocial intervention (CBT, CM, or MI) were consistent with the main analysis but owing to lack of power none of the analyses found a statistically significant difference between groups.

\section{Relative effect or mean difference}

There was a statistically significant difference between groups, in favor of psychosocial treatment (standardized mean difference $-0.20,95 \% \mathrm{Cl}-0.35$ to -0.05$)$.

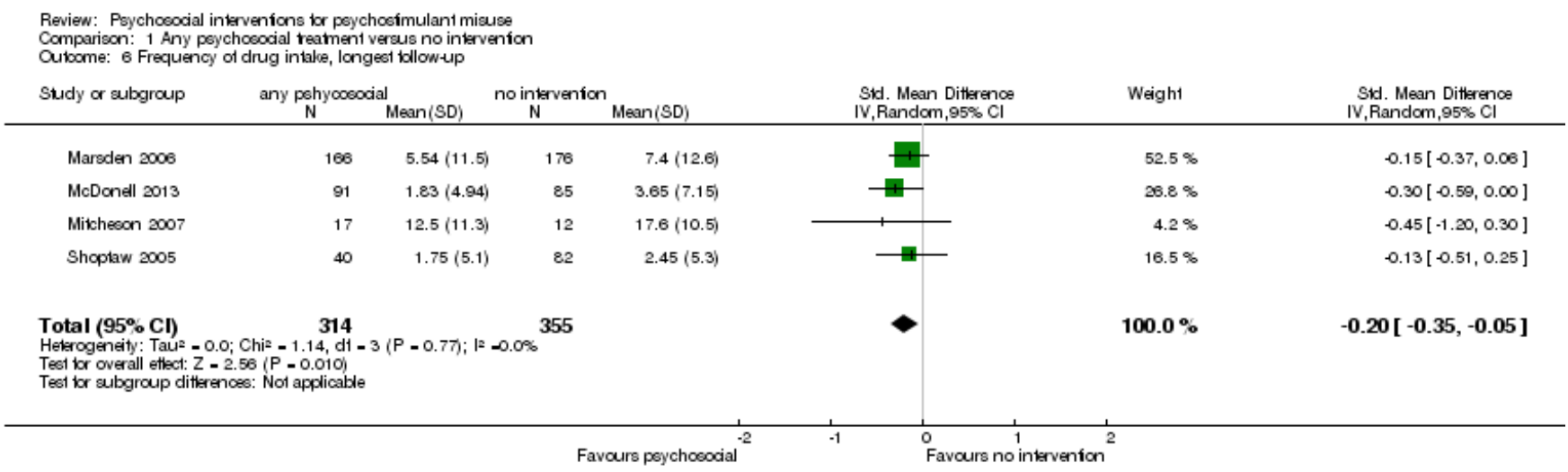

\section{Figure 5}

Open in figure viewer

Forest plot from Cochrane Review

\section{Reference}

Minozzi S, Saulle R, De Crescenzo F, Amato L. Psychosocial interventions for psychostimulant misuse. Cochrane Database of Systematic Reviews 2016, Issue 9. Art. No.: CD011866. DOI: 10.1002/14651858.CD011866.pub2. Search date November 2015

\section{> OUTCOME 1.5 Frequency of drug intake, end of treatment; Adverse events}

\section{Narrative result}

Reviewers found no RCTs assessing these outcomes.[6]

\section{Reference}


Minozzi S, Saulle R, De Crescenzo F, Amato L. Psychosocial interventions for psychostimulant misuse. Cochrane Database of Systematic Reviews 2016, Issue 9. Art. No.: CD011866. DOI: 10.1002/14651858.CD011866.pub2. Search date November 2015

\section{> Population, Intervention, Comparator}

\section{Population}

Adults (mean age 37 years, 63\% male) with a diagnosis of cocaine or amphetamine dependence based on DSM-III, DSM- IV, DSM-TR-IV or ICD-10 criteria, most with co-morbid alcohol dependence. In some RCTs, all participants also had opioid dependence and in some, all participants received treatment as usual

\section{Intervention}

Cognitive behavioral therapy [CBT], contingency management [CM], interpersonal therapy motivational interviewing [MI], psychodynamic therapy or 12-step facilitation for a mean 4 months

\section{Comparator}

No intervention

\section{Any psychosocial treatment versus treatment as usual (TAU)}

\section{> OUTCOME 2.1 Withdrawal from treatment (follow-up mean 10 months)}

\section{Quality of the evidence}

The reviewers performed a GRADE assessment of the quality of evidence for this outcome at this time point and stated that the evidence was moderate certainty. See Summary of findings from Cochrane Review

\section{Narrative result}

Six RCTs with 516 participants found that fewer people withdrew from treatment with psychosocial intervention compared with TAU.[7]

Most (420) participants received CBT.

\section{Relative effect or mean difference}

There was a statistically significant difference between groups, in favor of psychosocial treatment $(\mathrm{RR} 0.72,95 \% \mathrm{Cl}$ 0.59 to 0.89$)$. 


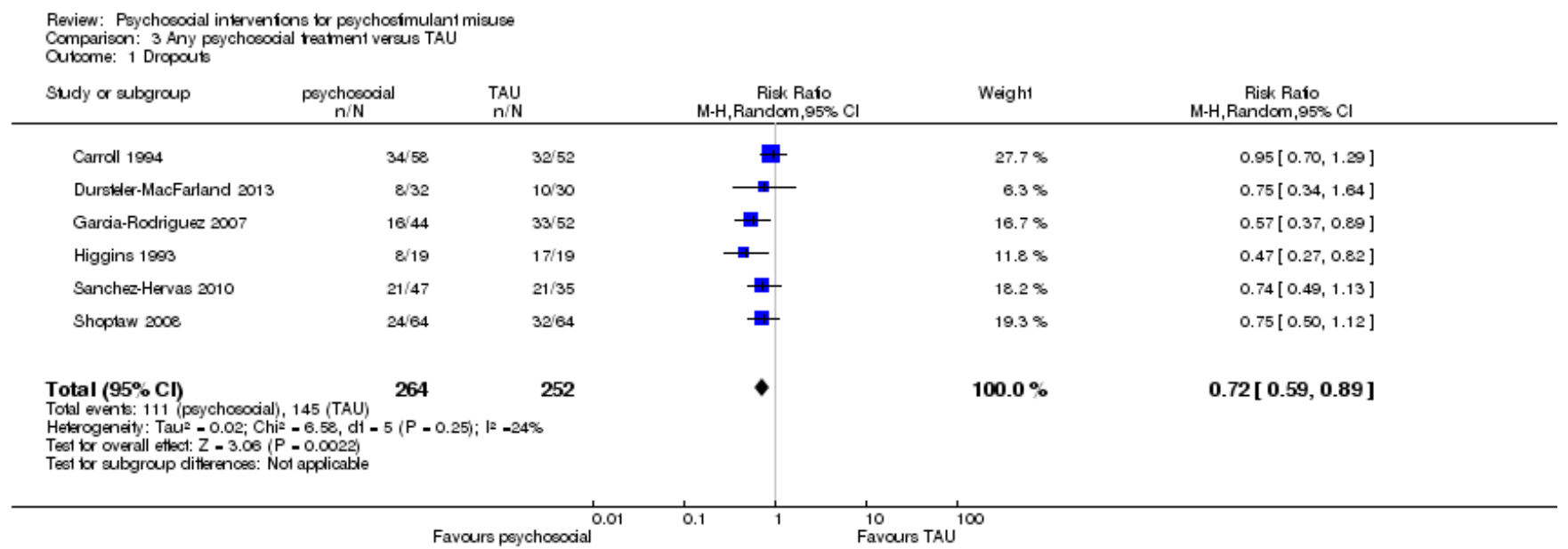

Figure 6

Open in figure viewer

Forest plot from Cochrane Review

\section{Absolute effect}

435 per 1000 people (95\% Cl 353 to 534) with psychosocial treatment compared with 600 per 1000 people with TAU.

\section{Reference}

Minozzi S, Saulle R, De Crescenzo F, Amato L. Psychosocial interventions for psychostimulant misuse. Cochrane Database of Systematic Reviews 2016, Issue 9. Art. No.: CD011866. DOI: 10.1002/14651858.CD011866.pub2. Search date November 2015

\section{$>$ OUTCOME 2.2 Continuous abstinence, end of treatment}

\section{Quality of the evidence}

The reviewers performed a GRADE assessment of the quality of evidence for this outcome at this time point and stated that the evidence was low certainty. See Summary of findings from Cochrane Review

\section{Narrative result}

Three RCTs with 264 participants receiving CBT (128 people) or CM (136 people) found no statistically significant difference between groups.[8]

\section{Relative effect or mean difference}

There was no statistically significant difference between groups (RR 1.15, 95\% Cl 0.91 to 1.46 ). 


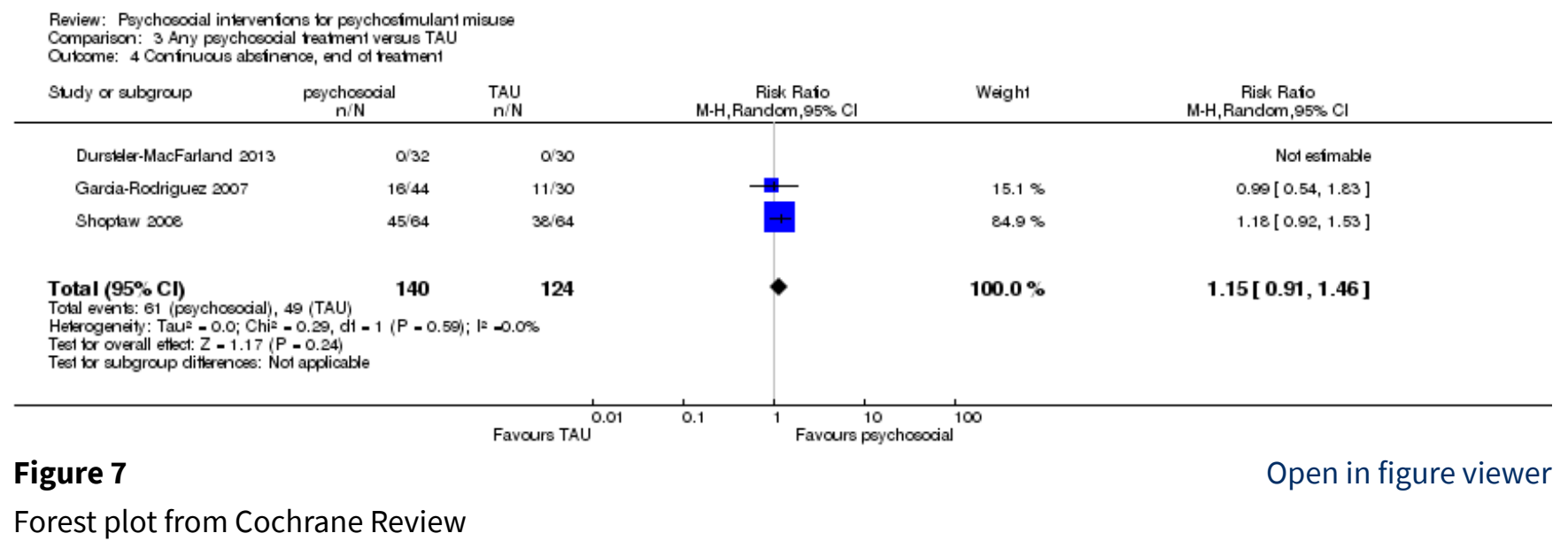

\section{Absolute effect}

423 per 1000 people (95\% Cl 333 to 536) with psychosocial treatment compared with 367 per 1000 people with TAU.

\section{Reference}

Minozzi S, Saulle R, De Crescenzo F, Amato L. Psychosocial interventions for psychostimulant misuse. Cochrane Database of Systematic Reviews 2016, Issue 9. Art. No.: CD011866. DOI: 10.1002/14651858.CD011866.pub2. Search date November 2015

\section{> OUTCOME 2.3 Frequency of drug intake, end of treatment or longest follow-up; Continuous abstinence, longest follow-up; Adverse events}

\section{Narrative result}

Reviewers found no RCTs assessing these outcomes.[9]

\section{Reference}

Minozzi S, Saulle R, De Crescenzo F, Amato L. Psychosocial interventions for psychostimulant misuse. Cochrane Database of Systematic Reviews 2016, Issue 9. Art. No.: CD011866. DOI: 10.1002/14651858.CD011866.pub2. Search date November 2015

\section{> Population, Intervention, Comparator}

\section{Population}

Adults (mean age 29-37 years, $63-90 \%$ male in 5 RCTs, $100 \%$ male in 1 RCT) with a diagnosis of cocaine or amphetamine dependence based on DSM-III-R or DSM- IV, criteria, some with co-morbid alcohol dependence Intervention

Cognitive behavioral therapy (CBT, 4 RCTs) or contingency management (CM, 2 RCTs)

\section{Comparator}


Treatment as usual: varied, where defined included pharmacotherapy and drug counseling

\section{Additional Information}

\section{DOI:}

https://doi.org/10.1002/cca.2598 scolaris.information.information.copy.clipboard

\section{First Published:}

\section{November 2019}

CCA Associate editor: Jonathan Livingstone-Banks (PhD), Research Fellow, University of Oxford, Oxfordshire, UK.

Contact the CCA team at clinicalanswers@cochrane.org. 